\title{
Development of the clinical reasoning of nurses of an emergency hospital service
}

\author{
Desenvolvimento do raciocínio clínico de enfermeiros de um serviço hospitalar de \\ emergência
}

Fernando Henrique Antunes Menegon ${ }^{1}$, José Luís Guedes dos Santos ${ }^{1}$, Natália Gonçalves ${ }^{1}$, Carolina Kahl ${ }^{1}$, Mayckel da Silva Barreto ${ }^{2}$, Francine Lima Gelbcke ${ }^{1}$

Objective: to understand the development of the clinical reasoning of nurses working in an emergency hospital service. Methods: qualitative research, with methodological reference of the Grounded Theory. Data collection took place through interviews, with a theoretical sample of 21 participants and analysis using substantive and theoretical coding. Results: the central category was identified as Knowing what to do, and four conceptual categories: 1) Uncovering the nurse's duties in the emergency service; 2) Improving clinical reasoning through professional experience; 3) Providing care with quality and safety for the patient; and 4) Conquering professional recognition from the health team. Conclusion: the development of nurses' clinical reasoning is a cumulative, experiential, and gradual process of knowing what to do in an emergency. It is based on the collaborative work with the health team and on the acquisition of technical-scientific knowledge to perform qualified assistance to patients.

Descriptors: Clinical Decision-Making; Thinking; Organization and Administration; Emergency Nursing; Emergency Service, Hospital.

Objetivo: compreender o desenvolvimento do raciocínio clínico de enfermeiros de um serviço hospitalar de emergência. Métodos: pesquisa qualitativa, com referencial metodológico da Teoria Fundamentada nos Dados. Coleta de dados ocorreu por meio de entrevistas, com amostragem teórica de 21 participantes e análise mediante codificação substantiva e teórica. Resultados: identificou-se a categoria central Sabendo o que fazer, e quatro categorias conceituais: 1) Descobrindo as atribuições do enfermeiro no serviço de emergência; 2) Aprimorando o raciocínio clínico por meio da experiência profissional; 3) Prestando assistência com qualidade e segurança para o paciente; e 4) Conquistando reconhecimento profissional da equipe de saúde. Conclusão: o desenvolvimento do raciocínio clínico do enfermeiro é um processo gradativo e experiencial cumulativo de "saber o que fazer" em emergência. Baseia-se no trabalho colaborativo com a equipe de saúde e na aquisição de conhecimentos técnico-científicos para realização de assistência qualificada a pacientes.

Descritores: Tomada de Decisão Clínica; Pensamento; Organização e Administração; Enfermagem em Emergência; Serviço Hospitalar de Emergência.

\footnotetext{
${ }^{1}$ Universidade Federal de Santa Catarina. Florianópolis, SC, Brazil.

${ }^{2}$ Faculdade de Filosofia, Ciências e Letras de Mandaguari. Mandaguari, PR, Brazil. 


\section{Introduction}

Clinical reasoning is one of the subjects that has gained relevance in the area of teaching and clinical practice in nursing. It can be defined as reflective, inductive, and deductive thinking, composed of acquired knowledge and personal experiences ${ }^{(1-2)}$. The term is associated with expressions such as critical thinking, critical judgment, creative thinking, and diagnostic reasoning, which represent attributes of nurses seeking the development of evidence-based practice ${ }^{(1)}$.

The main purpose of clinical reasoning is to allow decision-making regarding the diagnosis and therapeutics to be implemented to an individual with changes in the health-disease process ${ }^{(1-2)}$. In this sense, the development of clinical reasoning contributes to autonomy, leadership, and decision-making in the practice of nurses.

Specifically, in relation to emergency hospital services, the development of clinical reasoning is a constant need of nurses due to the complexity of the care provided, the constant demand for patients for care, and the wide turnover of patients ${ }^{(3-4)}$. This reality is often aggravated by organizational problems and lack of human and financial resources ${ }^{(3)}$.

Thus, the work in emergency services requires from nurses technical and scientific knowledge, rapid thinking, and readiness to make decisions in the development of care and management activities, aiming at a quality and safe care ${ }^{(3-4)}$. Among the competences of nurses working in emergency services, we highlight the ability to direct work, focusing on proactivity, professional autonomy, ability to influence people in leadership attitudes, and decision-making ${ }^{(5)}$.

Despite the relevance of the clinical reasoning of nurses in emergency hospital services, in the national and international literature, the subject is still little explored in comparison with other nurses' professional competences ${ }^{(6-7)}$. Most of the studies on clinical reasoning, especially in the Brazilian context, have been devoted to the discussion of strategies to develop clinical reasoning in the training of future nurses, such as clinical simulation, conceptual mapping, and problem-based learning ${ }^{(6-8)}$. Thus, in order to contribute to the nurses' practice in these scenarios and to advance in relation to the studies on this subject, the following guiding question was defined: how does the development of the clinical reasoning of nurses working in an emergency service occur?

The objective of this study was to understand the development of the clinical reasoning of nurses working an emergency hospital service.

\section{Methods}

This is a qualitative study that followed the theoretical-methodological framework of the Grounded Theory, a method that allows to understand the experiences and interactions of the actions of individuals and groups facing problems in a given context ${ }^{(9)}$.

The study scenario was the emergency service of a university hospital in Southern Brazil, which serves adult patients in the clinical and surgical specialties. The sector has two environments: internal emergency care, for risk classification to cases of greater severity; and, rest, for temporary admission. The nursing team is composed of 17 nurses and 43 nursing technicians.

Theoretical sampling ${ }^{(9)}$ was composed of 21 participants in a random manner, according to their availability. Participants were personally invited to participate in the approach in the work environment. Data collection began with seven nurses from the emergency sector (P1-P7). The selection of the first participants was intentional, considering the experience in relation to the investigated phenomenon. From the first seven interviews, and according to the Grounded Theory, hypotheses were generated that indicated the importance of the collaboration of more experienced nurses and of the health team to develop the nurses' clinical reasoning. The Theory allows the inclusion of other participants to assist in understanding the phenomenon under investigation, with a view to the theoretical saturation of the data ${ }^{(9)}$. 
Thus, two nurses with previous experience in the emergency service (P8 and P9), five nursing technicians (P10-P14) and two physicians (P15 and P16) from the emergency sector were also interviewed. The nurses with previous experience in the emergency sector worked in other units of the hospital and were identified from the interviews with emergency nurses, who emphasized the importance of these professionals for the development of clinical reasoning. The theoretical sample also included five nursing teachers (P17-P21) in the emergency area and/or with experience in teaching clinical reasoning in the undergraduate nursing course in the university to which the hospital is academically linked. The inclusion criterion was having a minimum time of six months of professional experience in the sector. Professionals on vacation or leave of any nature were excluded. There were no refusals to participate in the research.

Data were collected and analyzed simultaneously between March and July 2017, based on the assumption of constant comparative analysis ${ }^{(9)}$. Data collection was performed by the main researcher, who had no link with the interviewees, through an individual semi-structured interview, face to face, in the workplace or in an environment chosen by the participants. A script prepared by the researchers was used and validated and with experts in the Grounded Theory method. The interview questions sought to explore the process of developing the clinical reasoning of the emergency nurse. The interviews lasted an average of 20 minutes, were recorded in digital medium, transcribed in full, and validated by the research participants.

Data analysis followed coding steps of the classical line of Grounded Theory: substantive coding, which is divided into open and selective, and theoretical coding ${ }^{(9)}$. Substantive coding aims at the formation of concepts from the data. For this, in the open coding, the interviewees' statements were separated, compared, and conceptualized line by line, by means of codes. Sequentially, the codes were compared to each other and grouped into conceptual categories. As new evidence was gathered, these categories became dense, allowing visualization of interrelationships until the emergence of central category. Thus, selective coding was initiated, in which the coding was performed selectively in favor of the central category. The theoretical coding proceeded to the conceptualization and explanation of the relations between the data, from the grouping of fragmented elements by similarities ${ }^{(9)}$.

Throughout the process of constant comparative analysis, we used memos and diagrams that aided in the comparison of ideas and integration of results ${ }^{(9)}$. In the end, the theoretical construction was validated by researchers with experience in the subject and/or method.

Ethical aspects were respected, according to Resolution no 466/12 of the National Health Council, and the study was approved by the Ethics Research Committee, under opinion no 1,960,256 and Certificate of Presentation for Ethical Appreciation $\mathrm{n}$ 은 $63215316,7,0000,0121$. The anonymity of the participants was guaranteed using the letter "P" for participant, followed by the ordinal number of each interview.

\section{Results}

Participants were predominantly females (19, $90.4 \%$ ), aged between 28 and 64 years, and with mean age of 32 years. The length of professional experience ranged from two to 34 years, with an average of eight years. In relation to schooling, the majority had a graduate degree, nine $(42.8 \%)$ in master's degree and doctorate and seven $(23.8 \%)$ in specialization.

From the analysis of the data, the central category "Knowing what to do" and four conceptual categories were identified: 1) Uncovering the nurse's duties in the emergency service; 2) Improving clinical reasoning through professional experience; 3) Providing care with quality and safety for the patient; and 4) Conquering professional recognition from the health team. 


\section{Uncovering the nurse's duties in the emergency room}

Most of the nurses start the work in the emergency service right after graduating and without previous experience in this area of care. Because of this, it is common, in the first moment, to experience difficulties in adapting to the work context and to feel they have lack of knowledge and abilities to use clinical reasoning. I entered here right after graduation and had no experience in the emergency service ... (P1).... the nurses are in a new sector, in some cases they had never worked in an emergency and get a bit lost at first (P11). A newly hired professional in the service will have more difficulty than one who has a trajectory and other experiences (P18).

When inexperienced nurses start working in the emergency sector, they are often monitored for a month by more experienced nurses. This follow-up aims to help in the insertion of the new nurses, enabling them to know the norms, routines, and assistance behaviors of the emergency service. This moment of insertion in the service is crucial for the beginning of the development of the clinical reasoning, since the relationship with the more experienced professionals contributes to the learning of knowledge, skills, and attitudes for clinical evaluation of patients, leadership and decision-making in the nurse's practice. All of the staff stays as a shade for a month, both technicians and nurses, always stay with a colleague who already has more experience ... Then, my clinical reasoning began to develop (P5). When entering the sector, the main objective is for them to know the course of the unit and its routines for patient evaluation and decision-making... (P14).

Nurses seek help to clarify doubts regarding the diagnosis and treatment of patients under their care with other professionals in the sector, such as physicians, more experienced nurses and, mainly, nursing technicians. As these professionals have more accumulated practical experience in the sector, the nurses see them as allies in the planning of the treatment to the patients, aiming at decision-making with autonomy and safety. We used to clarify doubts with physicians, more experienced nurses, and we relied on the nursing technicians, who have great knowledge (P3). Nurses come in new and we already have baggage for having worked for many years, so we help them develop (P14).

Nurses also highlight the contribution of teachers to the development of clinical reasoning during professional training and theoretical-practical nursing activities. The presence of the teacher, explaining and guiding the student, allows a differentiated and more complete formation, as well as instigates students to search for knowledge. The teachers taught me and helped me develop my care practice. They encouraged me to seek knowledge (P2). There are many things that the teacher teaches, he is together, always explaining ... it is necessary to do a personal exercise in practice to begin the decision-making based on the clinical reasoning (P20).

\section{Improving clinical thinking through work expe- rience}

The improvement of clinical reasoning is a continuous process that occurs throughout the professional experience of nurses and from the influence of the specificities of the work in emergency. Overcrowding constantly seeks for service and work dynamics in this sector, making that care and management actions of nurses have to be accurate and often immediate. In this way, the clinical reasoning of nurses emerges as a set of knowledge about what should be done to quickly evaluate patients' signs and symptoms, aiming to identify the nursing care required. You start and are required to develop clinical reasoning to be able to work in this dynamic environment and this happen with time (P3). To develop reasoning, experience and practice in the field are required (P15). Care management has to be done quickly, because we have to look at the patient and see what he or she needs and connect with the diagnosis, with the possibility of illness and identify the nursing care... (P6).

The experience obtained from the professional practice and the collaborative work with the health team is complemented by the nurses through studies 
about the cases attended in the emergency service, which are carried out in the emergency sector itself or after the working day. Another strategy adopted by nurses is to attend improvement courses and/or professional specializations. I had to study when I entered into the emergency service because everything happens there. It is a great learning ... I attend training courses apart from work (P1). After any new illness, I came home and I had to study what I saw (P4).... in general, he (the nurse) will study, will devote himself outside his hourly workload, seeking literature, going to events, taking courses and specialization (P18).

\section{Providing quality patient care and patient safety}

Clinical reasoning enables nurses to predict and provide actions, materials and working conditions that contribute to the optimization of care and management of patient care. To make a decision regarding patient care, nurses are based on the observation and association of clinical signs that goes through the accomplishment of the systematization of nursing care and practice based on scientific evidence. We manage, before the physician prescribes, to list the care procedures, evaluate, and advance the preparations and get everything ready (P4). In the presence of various signs and symptoms, the nurse can make decisions to optimize the patient's signals and response (P18). If I do not use clinical reasoning, I will not make any decisions. I may even make it but it may not be the best decision and it will not be based on clinical evidence (P2).

Through clinical reasoning, nurses feel more confident and prepared to evaluate the clinical conditions of the patients, especially during the host with risk classification. Thus, nurses consider clinical reasoning as an instrument for quality of care and patient safety. With my reasoning, I can evaluate the patient much more safely. This also protects against errors, such as medications or wrong actions (P1). If you are in the host you need to see if that patient is severe and has to be taken care faster. You need to have this reasoning to correctly classify the patient (E2). I see the clinical reasoning as an instrument that guarantees the quality of care (P20).

\section{Conquering professional recognition from the health team}

As a consequence of the development of clinical reasoning, the nurses obtain professional recognition and are a reference for the development of care to the team in the emergency service. The demonstration of technical-scientific knowledge that underlies the clinical reasoning and the assertiveness in the decision-making makes the health team have confidence and trust in the nurses' behaviors. Of course, if they see that the nurse knows what he is doing, that he has clinical reasoning, as a consequence, the team will trust more in them (P6). Over time, we start relying on the nurse and in what he does (P14).

The nurses relate the professional autonomy to the decision-making process based on the demonstration of the clinical reasoning, through the technical-scientific knowledge about the care practice. There is this autonomy to decide many things... this gives more autonomy and empowerment to the nurse (P3).... nurses have a lot of autonomy (P16). And when the nurse makes the best decision, he will acquire autonomy... (P21).

The clinical reasoning of nurses also contributes to the improvement of communication and interpersonal relationship with the health team, since a relationship of mutual trust is established, which allows a better progress of work. Clinical reasoning facilitates the relationship with the technicians and the whole team... it makes the work lighter and smoother (P3). Relationships improve with certainty; this interaction, this communication, the relationship, it becomes better and more reliable (P19).

Figure 1 shows the diagram representing the articulation of the study results. Although the results have been described in ascending hierarchical form, the relations between the conceptual categories are dynamic. Sometimes nurses can experience different and new situations at work and feel more or less confident about clinical reasoning and, consequently, about decision-making at the emergency service. 


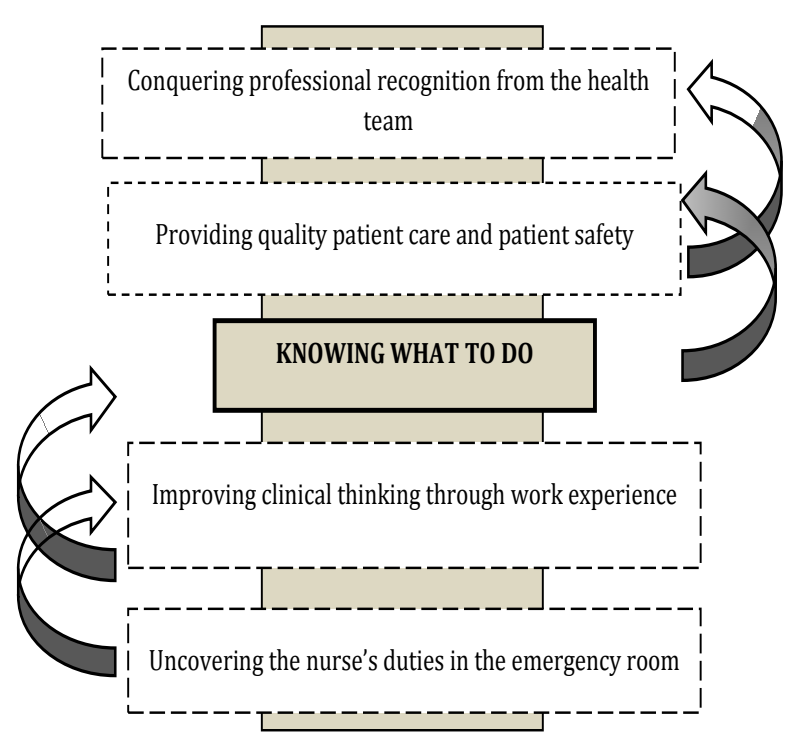

Figure 1 - Search results diagram

\section{Discussion}

Data collection was the limitation of this study, since the interviews were conducted at the workplace and during the participants' break, which caused some to be concerned about the return to activities. However, this facilitated access to the subjects and increased the number of interviewees. In addition, the study was restricted to one emergency service of a public and university hospital in Southern Brazil.

The clinical reasoning of the emergency nurse is a set of knowledge about what should be done to enable better patient care. The acquisition of this knowledge is an ongoing process that occurs throughout the professional practice, from the personal search for the development of skills, attitudes, and abilities, as well as the interaction with the professionals of the health team.

However, the insertion in the emergency service is marked by difficulties and adaptations, since the professional inexperience of the new nurses compromises the clinical reasoning. This moment of uncertainty and insecurity reinforces the need for professional and personal maturity to consolidate professional practice and develop clinical reasoning for decision-making in assistance ${ }^{(2,10)}$.

As a strategy to assist in the development of the clinical reasoning of the new nurses, most experienced nurses monitored the new ones, as a way of assisting the insertion of nurses in the new work environment and contribute to the learning of norms and behaviors that will guide the clinical reasoning. The literature reinforces the importance of an adaptation period for nurses in the first contact with the emergency hospital service, since it is an environment of constant changes, with complex organizational and social dynamics ${ }^{(11)}$. Similarly, according to the United Kingdom study, the achievement of confidence, leadership, and autonomy for the decision-making of nurses occurs with the development of professional practice $^{(12)}$.

Thus, the adaptation period in the emergency service is necessary, so that the nurse feels safe in relation to clinical reasoning as an expression of professional know-how. In addition, clinical reasoning is developed from collaborative work, which facilitates the acquisition of clinical experience by nurses. A study conducted in Canada also showed that monitoring the interaction by more experienced professionals provides greater safety and tranquility in the insertion and development of professional competencies of new nurses ${ }^{(13)}$.

It was also highlighted the personal search of nurses for knowledge to practice clinical reasoning, both through individual study, as well as through the search for complementary and postgraduate courses. This reinforces the need for constant updating and training of nurses, aiming at the development and professional competence to improve patient care in the nursing practice ${ }^{(13-14)}$.

Based on clinical reasoning and improvement of care skills, nurses participating in the study sought to contribute to patient safety in the emergency room. Thus, it is possible to corroborate the idea that care actions guided by clinical reasoning constitute a diffe- 
rential advantage for patient safety and quality $\operatorname{care}^{(1)}$.

Patient safety in an emergency unit involves both the development of the technical skills of professionals to perform procedures correctly and the knowledge of risk factors related to the care of patients in emergency situations ${ }^{(15)}$. The achievement of a positive patient safety culture requires the participation and involvement of managers and institutional leaders in the review of care processes and the elaboration of tools to improve quality ${ }^{(16)}$.

The development of clinical reasoning makes nurses feel more able to act in the emergency room. In this way, the professional identity of the nurse is reinforced as a critical-reflexive professional and a change agent committed to improving health care ${ }^{(17)}$. This was also observed in a study with nurses in Scotland and Greece, which showed the importance of clinical reasoning for decision-making regarding care and quality of care ${ }^{(18)}$.

Clinical reasoning also assists nurses in establishing better communication with the health team, building a relationship of mutual trust that favors the organization of care practice and articulation among workers. Similarly, results from a North American study on teamwork indicate that good relationships among health care providers contribute to the organization and qualification of care in the emergency service $^{(19)}$.

The effective relationship and communication between the health team, in turn, leads to feelings of trust in the care actions performed and/or prescribed by nurses, enabling the development of teamwork in a qualified manner. Still, as a consequence, the autonomy and proactivity of nurses in the decision-making process is increased through the identification and resolution of problems related to care ${ }^{(20)}$.

Therefore, the research reinforces the importance of the clinical reasoning of nurses for professional performance in emergency care. The importance of new studies about the mental models and processes through which nurses develop the clinical reasoning in emergency service is highlighted, seeking to systematize the technical-scientific knowledge necessary for the performance of care and managerial activities in these scenarios.

\section{Conclusion}

The development of the clinical reasoning of emergency nurses is a gradual, cumulative, and experiential process of knowing what to do. It is based on the collaborative work with the health team and on the acquisition of technical-scientific knowledge to provide qualified care to patients.

\section{Collaborations}

Menegon FHA and Santos JLG contributed to the design and conception, analysis, and interpretation of data. Gonçalves N, Kahl C, Barreto MS and Gelbcke FL collaborated with writing of the manuscript, relevant critical revision of the intellectual content, and final approval of the version to be published.

\section{References}

1. Carbogim FC, Oliveira LB, Püschel VAA. Critical thinking: concept analysis from the perspective of Rodger's evolutionary method of concept analysis. Rev Latino-Am Enfermagem. 2016; 24:e2785. doi: dx.doi.org/10.1590/1518-8345.1191.2785

2. Van Graan AC, Williams MJ, Koen MP. Professional nurses' understanding of clinical judgement: a contextual inquiry. Health Sa Gesondheid. 2016; 21:280-93. doi: https://doi.org/10.1016/j. hsag.2016.04.001

3. Rossetti AC, Gaidzinski RR, Fugulin FMT. Nursing workload in the emergency department: a methodological proposal. Rev Latino-Am Enfermagem. 2013; 21(n.esp.):225-32. doi: dx.doi. org/10.1590/S0104-11692013000700028 
4. Santos JLG, Menegon FHA, De Pin SB, Erdmann $\mathrm{AL}$, Oliveira RJT, Costa IAP. The nurse's work environment in a hospital emergency service. Rev Rene. 2017; 18(2):195-203. doi: 10.15253/21756783.2017000200008

5. Holanda FL, Marra CC, Cunha ICKO. Construction of a professional competency matrix of the nurse in emergency services. Acta Paul Enferm. 2014; 27(4):373-9. doi: dx.doi.org/10.1590/19820194201400062

6. Crossetti MGO, Bittencourt GKGD, Lima AAA, Góes MGO, Saurin G. Structural elements of critical thinking of nurses in emergency care. Rev Gaúcha Enferm. 2014; 35(3):55-60. doi: dx.doi. org/10.1590/1983-1447.2014.03.45947

7. Pérez EZ, Canut MTL, Pegueroles AF, Llobet MP, Arroyo CM, Merino JR. Critical thinking in nursing: Scoping review of the literature. Int J Nurs Pract. 2015; 21(6):820-30. doi: https://doi. org/10.1111/ijn.12347

8. Smyth O, McCabe C. Think and think again! Clinical decision making by advanced nurse practitioners in the Emergency Department. Int Emerg Nurs. 2017; 31:72-4. doi: https://doi.org/10.1016/j. ienj.2016.08.001

9. Andrews T, Mariano GJS, Santos JLG, KoerberTimmons K, Silva FH. The methodology of classic grounded theory: considerations on its application in nursing research. Texto Contexto Enferm. 2017; 26(4)e1560017. doi: http://dx.doi. org/10.1590/0104-070720170001560017

10. Monteiro RP, Jung W, Lazzari DD, Nascimento ERP, Dalamaria JM. The professional transition process from the perspective of nursing technicians who have become nurses. Rev Eletr Enf. 2014; 16(4):777-86. doi: http://dx.doi.org/10.5216/ ree.v16i4.24129

11. Parker V, Giles M, Lantry G, McMillan M. New graduate nurses' experiences in their first year of practice. Nurse Educ Today. 2014; 34(1):150-6. doi: https://doi.org/10.1016/j.nedt.2012.07.003

12. Narayanasamy A, Penney V. Coaching to promote professional development in nursing practice. $\mathrm{Br}$ J Nur. 2014; 23(11):568-73. doi: https://doi. org/10.12968/bjon.2014.23.11.568
13. Pfaff KA, Baxter PE, Jack SM, Ploeg J. Exploring new graduate nurse confidence in interprofessional collaboration: a mixed methods study. Int J Nurs Stud. 2014; 51(8):1142-52. doi: https://doi. org/10.1016/j.ijnurstu.2014.01.001

14. Kinsella D, Fry M, Zecchin A. Motivational factors influencing nurses to undertake postgraduate hospital-based education. Nurse Educ Pract. 2018; 31:54-60. doi: https://doi.org/10.1016/j. nepr.2018.04.011

15. Bampi R, Lorenzini E, Krauzer IM, Ferraz L, Silva EF, Dall'Agno CM. Perspectives of the nursing team on patient safety in an emergency unit. Rev Enferm UFPE on line [Internet]. 2017 [cited Apr. 13, 2019]; 11(2):584-90. Available from: https:// periodicos.ufpe.br/revistas/revistaenfermagem/ article/view/11977

16. Costa DB, Ramos D, Gabriel CS, Bernardes A. Patient safety culture: evaluation by nursing professionals. Texto Contexto Enferm. 2018; 27(3):e2670016. doi: http://dx.doi. org/10.1590/0104-070720180002670016

17. Lima RBS, Dias MSA, Brito MCC, Silva AV, Silva LMS, Coutinho JFV. Social representations of students in the construction of the professional identity of nurses. Rev Rene. 2018; 19:e32468. doi: http:// dx.doi.org/10.15253/2175-6783.20181932468

18. Kydonaki K, Huby G, Tocher J, Aitken LM. Understanding nurses' decision-making when managing weaning from mechanical ventilation: a study of novice and experienced critical care nurses in Scotland and Greece. J Clin Nur. 2016; 25(3-4):434-44. doi: doi.org/10.1111/jocn. 13070

19. Ajeigbe DO, McNeese-Smith D, Phillips LR, Leach LS. Effect of nurse-physician teamwork in the emergency department nurse and physician perception of job satisfaction. J Nurs Care. 2014; 3:141. doi: http://dx.doi.org/10.4172/21671168.1000141

20. Tiffen J, Corbridge SJ, Slimmer L. Enhancing clinical decision making: development of a contiguous definition and conceptual framework. J Prof Nurs. 2014; 30(5):399-405. doi: https://doi. org/10.1016/j.profnurs.2014.01.006 